\title{
CONTEXTUALIZAÇÃo SOBRE ÁGUA E Aedes aegypti NO ENSINO FUNDAMENTAL DE UMA ESCOLA PÚBLICA EM ALEGRE-ES
}

\author{
Lorena Souza Castro ${ }^{1}$ \\ Keminy Ribett Bautz ${ }^{2}$ \\ Elaine Gimenez Guimarães ${ }^{3}$ \\ Anderson Lopes Peçanha ${ }^{4}$
}

Resumo: A contextualização dos conteúdos no ensino fundamental é de extrema importância para a compreensão dos assuntos que permeiam a sociedade. O objetivo da contextualização sobre a água permite sensibilizar os alunos para um dos assuntos mais evidentes no ano vigente. $A$ discussão da problemática é relevante para o profissional em formação e contribui para a reformulação do pensamento de ideologias, para uma postura crítica na sociedade na qual estamos inseridos. A mediação ocorreu por meio de palestras, utilizando materiais didáticos como flanelógrafo, jogo lúdico e modelos didáticos em biscuit com os alunos do $7^{\circ}$ ano de uma escola pública no município de Alegre, ES. Neste trabalho foram explanadas também dúvidas a respeito de medidas profiláticas de combate ao mosquito Aedes aegypti.

Palavras-chave: Jogo lúdico; Dengue; Zika; Chikungunya; Saúde.

\footnotetext{
${ }^{1}$ Ciências Biológicas/Universidade Federal do Espírito Santo, Brasil. E-mail: lorenascast@gmail.com.

${ }^{2}$ Ciências Biológicas/Universidade Federal do Espírito Santo, Brasil. E-mail: keminy.bautz@gmail.com.

${ }^{3}$ Ciências Biológicas/Universidade Federal do Espírito Santo, Brasil. E-mail: elainegimenezg@gmail.com.

${ }^{4}$ Departamento de Biologia/ Universidade Federal do Espírito Santo, Brasil. E-mail: anderson.pecanha@ufes.br.
} 